\section{Severe osteoarticular involvement in isotretinoin- triggered acne fulminans: two cases successfully treated with anakinra}

\section{Editor}

Acne fulminans (AF) is a severe form of inflammatory and ulcerated acne associated with fever, malaise, joint swellings and polyarthralgia. ${ }^{1}$ Osteoarticular lesions are often described and can be radiologically indistinguishable from those observed in synovitis, acne, pustulosis, hyperostosis and osteitis (SAPHO) syndrome. ${ }^{2,3}$ SAPHO is an autoinflammatory disease characterized by osteoarticular and cutaneous manifestations, the latter including nodular and fulminans acne, hidradenitis suppurativa and palmoplantar pustulosis. ${ }^{3}$ Thus, AF is considered part of the SAPHO spectrum. ${ }^{1}$

Oral isotretinoin (13-cis retinoic acid) is recommended for the treatment of severe nodular acne. ${ }^{4}$ It has also been used in $\mathrm{AF}^{1}$ that, paradoxically, can be triggered by isotretinoin. ${ }^{5}$

We report two male adolescents with isotretinoin-triggered $\mathrm{AF}$ and severe osteoarticular manifestations. In both cases, treatment with a recombinant IL-1 receptor antagonist, anakinra, bisphosphonates and a short course of corticosteroids led to rapid disease control.

A 17 -year-old male was treated with $0.6 \mathrm{mg} / \mathrm{kg} / \mathrm{day}$ oral isotretinoin for nodular acne. After 4 weeks, he presented ulcerated nodules on the face and trunk healing with hypertrophic scars (Fig. 1), associated with back, chest and hip pain, joint swelling and functional impairment. Isotretinoin was discontinued. C-reactive protein was $3.23 \mathrm{mg} / \mathrm{dL}$, ESR $46 \mathrm{~mm} / \mathrm{h}$ and WBC count $14000 / \mu \mathrm{L}$ (neutrophils $83.9 \%$ ). Whole-body magnetic resonance imaging (MRI) revealed sternoclavicular joint involvement extending to the clavicles, soft tissues and sternum, as well as multiple hyperintense lesions of L2 vertebra, left iliac crest and left distal femoral metaphysis (Fig. 1). Bone scintigraphy showed increased uptake at the same structures (Fig. 1). We administered prednisone $(0.8 \mathrm{mg} / \mathrm{kg} /$ day $)$ tapered over 2 weeks, three pamidronate intravenous infusions $(1 \mathrm{mg} / \mathrm{kg})$ and anakinra subcutaneous injections (100 mg/day) for 3 months. A marked osteoarticular and cutaneous improvement was observed within 2 weeks, with clinical remission in 1 month without side-effects. Follow-up MRI documented lesion resolution and the disease did not recur over the last 3 years.
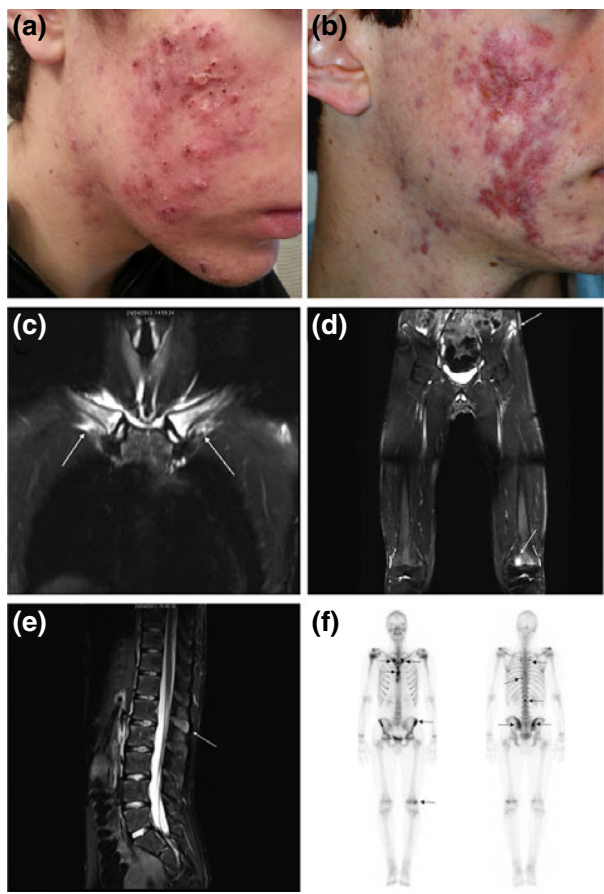

(f)

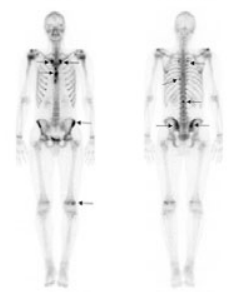

Figure 1 Case 1: Confluent papulonodular and cystic inflammatory acne lesions on the right cheek shortly after isotretinoin discontinuation (a); residual erythema and scarring in the same areas after 2-week anakinra treatment (b). Contiguous sagittal and coronal whole-body STIR MR image (c-e) and whole-body bone scan $99 m T c-M D P(f)$. Sternoclavicular involvement extending to the clavicles, the soft tissues and the sternum (c, arrows). Hyperintensity of the left iliac crest (d, arrow) and adjacent soft tissue, and left distal femoral metaphysis (d, arrow). L2 vertebra hyperintensity (e, arrow). Increased radiotracer uptake at the same areas (f, arrows).

The second patient, a 17-year-old male, was admitted to our emergency department for back and chest pain, weight loss and low-grade fever in the last 10 days. Isotretinoin $(0.8 \mathrm{mg} / \mathrm{kg} /$ day $)$ had been administered for severe acne for 6 weeks and stopped 5 days before. Physical examination revealed cystic and ulcerated acne, reduced hip movement range with sternal and lumbar spine pain. C-reactive protein was $2.68 \mathrm{mg} / \mathrm{dL}$, ESR $35 \mathrm{~mm} / \mathrm{h}$ and WBC count $12010 / \mu \mathrm{L}$ (71.7\% neutrophils). Whole-body MRI and bone scintigraphy showed sternoclavicular, right shoulder, sacroiliac and long bone involvement. We administered prednisone $2 \mathrm{mg} / \mathrm{kg}$ /day, gradually tapered over 8 weeks, three pamidronate infusions $(1 \mathrm{mg} / \mathrm{kg})$ and anakinra $(100 \mathrm{mg} /$ day), with marked reduction of symptoms within 2 weeks. Follow-up MRI and bone scintigraphy performed at 7, 12 and 
Table 1 Cases of SAPHO syndrome treated with anakinra

\begin{tabular}{|c|c|c|c|c|c|c|c|c|}
\hline $\begin{array}{l}\text { Patient } \\
\text { number }\end{array}$ & Age & Sex & $\begin{array}{l}\text { SAPHO skin } \\
\text { manifestation }\end{array}$ & Previous therapies & $\begin{array}{l}\text { Response to } \\
\text { treatment (weeks) }\end{array}$ & $\begin{array}{l}\text { Loss of efficacy } \\
\text { and relapses }\end{array}$ & $\begin{array}{l}\text { Adverse } \\
\text { reaction }\end{array}$ & Reference \\
\hline 1 & 54 & $\mathrm{~F}$ & PPP & $\begin{array}{l}\text { NSAIDs, CCS, MTX, } \\
\text { LEF }\end{array}$ & Yes (1) & No & Yes* & 9 \\
\hline 2 & 41 & M & PPP & $\begin{array}{l}\text { NSAIDs, CCS, } \\
\text { colchicines, SSZ, retinoids }\end{array}$ & Yes $(<2)$ & No & No & 9 \\
\hline 3 & 49 & $\mathrm{~F}$ & HS & $\begin{array}{l}\text { NSAIDs, MTX, INFX, } \\
\text { retinoids }\end{array}$ & Yes (2) & No & No & 9 \\
\hline 4 & 53 & $\mathrm{~F}$ & PPP & $\begin{array}{l}\text { NSAIDs, CCS, MTX, } \\
\text { colchicines, INFX, } \\
\text { ETN, ADA }\end{array}$ & Yes (4) & No & No & 9 \\
\hline 5 & 25 & $\mathrm{~F}$ & PPP & NSAIDs, pamidronate & Yes (2) & No & No & 9 \\
\hline 6 & 37 & $M$ & PPP & $\begin{array}{l}\text { NSAIDs, pamidronate, } \\
\text { ETN, ADA }\end{array}$ & No & No & No & 9 \\
\hline 7 & 47 & $\mathrm{~F}$ & PPP & SSZ & Yes (8) & No & No & 8 \\
\hline 8 & NS & NS & PPP & $\begin{array}{l}\text { NSAIDs, CCS, LEF, MTX, } \\
\text { pamidronate, tetracyclines, } \\
\text { INFX, ETN, ADA }\end{array}$ & Yes (rapid action) & No & Yes* & 7 \\
\hline
\end{tabular}

CCS, corticosteroids; MTX, methotrexate; LEF, leflunomide; SSZ, sulfasalazine; INFX, infliximab; ETN, etanercept; ADA, adalimumab; PPP, palmoplantar pustulosis; HS, hidradenitis suppurativa; NS, not specified.

*Injection site reaction.

18 months revealed a progressive improvement. Anakinra therapy is still ongoing 2 years after discharge (100 mg every 3 days), without side-effects.

Understanding of SAPHO pathogenesis is still limited. Proinflammatory cytokines such as TNF- $\alpha$ and IL- 1 seem to play a central role, ${ }^{6-8}$ and the recombinant IL-1 receptor antagonist anakinra has proven rapidly effective in a limited number of patients with SAPHO syndrome $e^{7-10}$ (Table 1).

Although mild and transient myalgia and arthralgia are frequent during isotretinoin treatment, severe osteoarticular manifestations of AF occur rarely, usually within few weeks from isotretinoin starting. ${ }^{5}$ This suggests a possible genetic susceptibility to SAPHO.

In conclusion, we describe for the first time the successful use of anakinra in two cases of AF presenting radiologically documented osteoarticular manifestations. The rapid and sustained osteoarticular and acne therapeutic response is in keeping with the IL-1 role in SAPHO pathogenesis. Of note, the combined therapy with anakinra and pamidronate allowed to significantly shorten corticosteroid course.

Bone scintigraphy alterations observed in about $70 \%$ of AF cases $^{2}$ indicate that the large majority of patients with AF have SAPHO syndrome. Patients with AF should be systemically screened by whole-body bone scintigraphy and/or MRI to ascertain osteoarticular lesions, and ensure an appropriate management and follow-up.

T. Oranges, ${ }^{1}$ A. Insalaco, ${ }^{2}$ A. Diociaiuti, ${ }^{3}$ C. Carnevale ${ }^{3}$ R. Strippoli, ${ }^{4}$ G. Zambruno, ${ }^{3}$ P. Tomà, ${ }^{5}$ M. El Hachem ${ }^{3, \star}$

${ }^{1}$ Department of Dermatology, Pisa University, Pisa, Italy, ${ }^{2}$ Division of Rheumatology, Bambino Gesu Children's Hospital, IRCCS, Rome, Italy, ${ }^{3}$ Dermatology, Bambino Gesù Children's Hospital, IRCCS, Rome, Italy,
${ }^{4}$ Department of Cellular Biotechnologies and Hematology, Section of Molecular Genetics, Sapienza University, Rome, Italy, ${ }^{5}$ Department of Imaging, Bambino Gesù Children's Hospital, IRCCS, Rome, Italy *Correspondence: M. El Hachem. E-mail: may.elhachem@opbg.net

\section{References}

1 Zaba R, Schwartz R, Jarmuda S, Czarnecka-Operacz M, Silny W. Acne fulminans: explosive systemic form of acne. J Eur Acad Dermatol Venereol 2011; 25: 501-507.

2 Laasonen LS, Karvonen SL, Reunala TL. Bone disease in adolescents with acne fulminans and severe cystic acne: radiologic and scintigraphic findings. AJR Am J Roentgenol 1994; 162: 1161-1165.

3 Nguyen MT, Borchers A, Selmi C, Naguwa SM, Cheema G, Gershwin ME. The SAPHO syndrome. Semin Arthritis Rheum 2012; 42: 254-265.

4 Nast A, Dréno B, Bettoli V et al. European evidence-based (S3) guideline for the treatment of acne - update 2016 - short version. J Eur Acad Dermatol Venereol 2016; 30: 1261-1268.

5 Barbareschi M, Paresce E, Chiaratti A, Ferla Lodigiani A, Clerici G, Greppi F. Unilateral sacroiliitis associated with systemic isotretinoin treatment. Int J Dermatol 2010; 49: 331-333.

6 Cassel SL, Janczy JR, Bing X et al. Inflammasome-independent IL-1 $\beta$ mediates autoinflammatory disease in Pstpip2-deficient mice. Proc Natl Acad Sci USA 2014; 111: 1072-1077.

7 Firinu D, Garcia-Larsen V, Manconi PE, Del Giacco SR. SAPHO syndrome: current developments and approaches to clinical treatment. Curr Rheumatol Rep 2016; 18: 35.

8 Firinu D, Murgia G, Lorrai MM et al. Biological treatments for SAPHO syndrome: an update. Inflamm Allergy Drug Targets 2014; 13: 199-205.

9 Colina M, Pizzirani C, Khodeir M et al. Dysregulation of P2X7 receptorinflammasome axis in SAPHO syndrome: successful treatment with anakinra. Rheumatology (Oxford) 2010; 49: 1416-1418.

10 Wendling D, Prati C, Aubin F. Anakinra treatment of SAPHO syndrome: short-term results of an open study. Ann Rheum Dis 2012; 71: 1098-1100.

DOI: $10.1111 / j d v .14022$ 